\title{
PELAYANAN FISIOTERAPI PEMERIKSAAN BENTUK ARKUS PEDIS (NORMAL FOOT, FLAT FOOT, DAN CAVUS FOOT) DAN PEMERIKSAAN POLA BERJALAN (STRIDE LENGTH, STEP LENGTH, CADENCE, DAN SPEED) PADA ANAK DI SDN 8 DAUH PURI DENPASAR
}

\author{
Ni Komang Ayu Juni Antar ${ }^{1}$, Made Hendra Satria Nugraha², Anak Ayu Nyoman Trisna Narta \\ Dewi $^{3}$
}

\begin{abstract}
ABSTRAK
Masa anak-anak merupakan masa yang sangat penting untuk memperhatikan pertumbuhan dan perkembangan. Hal tersebut dapat meminimalisir adanya kelainan pertumbuhan dan perkembangan yang bersifat permanen. Tujuan dari pengabdian ini adalah untuk melakukan pemeriksaan bentuk arkus pedis dan pola berjalan pada anak. Pengabdian dilakukan pada siswasiswi Sekolah Dasar Negeri 8 Dauh Puri. Pengklasifikasian tipe arkus dalam penelitian ini menggunakan Clarke's Angle, sehingga didapatkan jumlah masing-masing kelompok yaitu normal foot berjumlah 40 orang, flat foot berjumlah 40 orang, dan cavus foot berjumlah 33 orang. Berdasarkan hasil pemeriksaan dapat disimpulkan bahwa tipe normal foot memiliki nilai cadence (jumlah langkah), stride length, step length, dan speed yang lebih besar dari pada flat foot dan cavus foot.
\end{abstract}

Kata kunci: arkus pedis, stride length, step length, cadence, speed

\begin{abstract}
Childhood is a very important period to pay attention to growth and development. This can minimize the existence of permanent growth and development abnormalities. The purpose of this service is to examine the pedis arch shape and walking patterns in children. Dedication is done to students at Dauh Puri 8 Elementary School. Archival type classification in this study used Clarke 'Angle, so that the number of each group that is normal foot was 40 people, flat foot was 40 people, and cavus foot was 33 people. Based on the results of the examination it can be concluded that the normal foot type has a cadence value (number of steps), stride length, step length, and speed that is greater than the flat foot and cavus foot.
\end{abstract}

Keywords: plantar arch, stride length, step length, cadence, speed

\section{PENDAHULUAN}

Masa anak-anak merupakan masa yang sangat penting untuk memperhatikan pertumbuhan dan perkembangan. Hal tersebut dapat meminimalisir adanya kelainan pertumbuhan dan

1 Departemen Fisioterapi, Fakultas Kedokteran, Universitas Udayana

2 Departemen Fisioterapi, Fakultas Kedokteran, Universitas Udayana

3 Departemen Fisioterapi, Fakultas Kedokteran, Universitas Udayana 
perkembangan yang bersifat permanen. Aspek-aspek perkembangan anak meliputi fisik-motorik, intelektual, moral, emosional, sosial, bahasa dan kreativitas. Kemampuan motorik merupakan kemampuan yang berhubungan dengan gerakan-gerakan tubuh. Salah satu perkembangan motorik anak yang paling penting ialah berjalan. Berjalan sering dianggap sebagai pencapaian puncak dari aktivitas motorik kasar anak. Berjalan merupakan salah satu keterampilan motorik yang paling jelas menandai kemandirian pada anak (Suhartini, 2005). Beberapa orang tua kerap merasa khawatir apabila pola berjalan anak dilihat seperti tidak normal. Hal ini dapat mengindikasikan adanya kelainan pada struktur kaki. Gerak dasar jalan merupakan salah satu gerak dasar lokomotor yang merupakan salah satu bagian dari gerak dasar fundamental (fundamental basic movement). Gerak lokomotor merupakan jenis gerakan yang ditandai dengan pergerakan seluruh tubuh, proses perpindahan tempat atau titik berat badan dari satu bidang tumpu ke bidang tumpu lainnya (Nugroho, 2012). Berjalan terlihat sederhana namun melibatkan mekanisme yang kompleks.

Arkus pedis memiliki fungsi untuk membantu efisien fungsi kaki. Struktur pedis ini juga terdiri dari dua fungsi, yaitu menahan berat badan dan pergerakan berjalan atau berlari (Zulham, 2016). Secara umum bentuk arkus longitudinal medial terbagi menjadi tiga jenis yaitu normal foot, flat foot, dan cavus foot. Normal foot adalah kondisi pedis memiliki lengkungan atau arkus pedis yang normal. Flat foot atau biasa disebut dengan pes planus atau kaki datar memiliki kondisi pedis dimana lengkung kaki menghilang yang ditandai dengan bentuk kaki yang rata. Cavus foot atau biasa disebut dengan pes cavus ialah kondisi lengkungan pedis yang tinggi (Nurohman et al., 2017). Saat berjalan jauh, kelompok dengan flat foot akan lebih mudah merasakan lelah pada kakinya dibandingkan kelompok dengan cavus foot yang dapat berjalan lebih jauh dan tidak lebih mudah merasakan lelah pada kakinya. Hal ini dikarenakan adanya perbedaan tekanan dan tension pada plantar antara kedua kelompok. Melihat hal tersebut, dirasa penting untuk melakukan pemeriksaan secara dini mengenai tipe arkus pedis dan pemeriksaan pola berjalan pada anak usia sekolah dasar untuk dapat memberikan wawasan kepada anak, orang tua dan lingkungan sekitar, serta sebagai edukasi tindak lanjut dalam rangka melakukan pencegahan munculnya dampak lebih lanjut sehingga tercapainya kemampuan gerak fungsional yang maksimal.

Fisioterapi sebagai salah satu cabang ilmu kesehatan yang sangat erat kaitannya terhadap kemampuan gerak dan fungsional individu tentunya memiliki peran yang sangat penting dalam situasi ini yaitu dapat berkontribusi dalam melakukan pelayanan fisioterapi berupa pemeriksaan arkus pedis dengan menggunakan footprint test yang selanjutnya menilai kategori tipe arkus menggunakan Clarke's angle. Pada pemeriksaan pola berjalan menggunakan spatial gait parameters dan temporal gait parameters yang terdiri dari : (1). Stride Length dan Step Length: Pengukuran parameter ini ialah kaki subjek akan menapak pada matras spons yang telah berisi tinta lalu berjalan di atas kertas panjang dengan tatapan menghadap ke depan serta berjalan senyaman mungkin. Sidik pedis yang akan diukur ialah setelah 3 langkah (Permatasari \& Winarni, 2017). Pengukuran ini akan dinilai dari sidik pedis berisikan tinta yang menempel pada kertas (Neumann, 2010). (2). Cadence: Cadence merupakan jumlah langkah dalam waktu tertentu. Pengukuran untuk menilai cadence ialah subjek diminta untuk berjalan selama satu menit lalu hitung jumlah langkah dalam satu menit. Subjek berjalan dengan tatapan menghadap ke depan serta berjalan senyaman mungkin (Kharb et al., 2011). (3). Speed: Speed atau kecepatan ialah jarak yang dapat ditempuh dalam waktu tertentu. Kecepatan sesaat bervariasi selama siklus berjalan namun kecepatan rata-rata adalah hasil dari irama (cadence) dan stride length. Cadence dapat dihitung dengan jumlah langkah (step) dalam satu menit atau 60 detik, sehingga sesuai dengan half 
stride length per 60 detik atau full stride length per 120 detik. Kecepatan dapat dihitung dengan: Speed $(\mathrm{m} / \mathrm{s})=$ stride length $(\mathrm{m}) \times$ cadence $($ step/min $) / 120($ Kharb et al., 2011)

Berdasarkan data studi pendahuluan yang dilakukan anak usia sekolah dasar di Kecamatan Denpasar Barat, pihak sekolah mengatakan bahwa belum pernah dilaksanakan pemeriksaan atau pelayanan fisioterapi terkait dengan pemeriksaan arkus pedis dan pemeriksaan pola berjalan pada siswa dan siswi mereka. Berdasarkan permasalahan di atas, maka penting dilakukan pelayanan kesehatan berupa pemeriksaan tipe arkus pedis (normal foot, flat foot, dan cavus foot) dan pemeriksaan pola berjalan pada anak usia sekolah dasar di Kecamatan Denpasar Barat.

\section{METODE PELAKSANAAN}

Pelaksanan pelayanan kesehatan fisioterapi pada masyarakat dimulai pada tahap persiapan dengan melakukan kunjungan SDN 8 Dauh Puri Denpasar untuk melakukan perijinan, serta survey terkait dengan informasi awal yang diperlukan. Pada tahap ini, melibatkan beberapa staff dosen dan juga mahasiswa di Program Studi Sarjana Fisioterapi dan Profesi Fisioterapi FK Unud. Pada tahap ini, luaran yang diharapkan adalah terjalinnya kerja sama antara Program Studi Sarjana Fisioterapi dan Profesi Fisioterapi FK Unud dengan pihak SDN 8 Dauh Puri Denpasar serta terciptanya strategi pemecahan masalah terhadap tujuan pengabdian masyarakat yang akan dilakukan.

Pada tahap pelaksanaan, sebelum pemeriksaan arkus pedis dan pemeriksaan pola jalan dilakukan, terlebih dahulu dilakukan sosialisasi mengenai kegiatan yang akan berlangsung, dari tujuan, manfaat, peran fisioterapi dalam memberikan pelayanan kesehatan serta mekanisme pelaksanaan pemeriksaan. Setelah sosialisasi selesai barulah dilanjutkan dengan pemeriksaan arkus pedis dan pemeriksaan pola jalan.

Setelah selesai pemeriksaan dan didapatkan hasil maka selanjutnya akan diberikan sosialisasi kembali berupa edukasi serta masukan kepada anak-anak beserta orang tua tentang gait parameter pada anak dengan masing-masing tipe arkus pedis khususnya tipe flat foot dan cavus foot sehingga dapat memberikan informasi dini untuk modifikasi gaya hidup serta menanggulangi lebih awal jika terdapat perbedaan gait parameter pada flat foot dan cavus foot dengan melakukan exercise dan terapi yang tepat.

\section{HASIL DAN PEMBAHASAN}

Pengabdian ini bertujuan untuk menambah wawasan dan sebagai edukasi serta masukan kepada anak-anak beserta orang tua tentang gait parameter pada anak dengan masing-masing tipe arkus pedis khususnya tipe flat foot dan cavus foot sehingga dapat memberikan informasi dini untuk modifikasi gaya hidup serta menanggulangi lebih awal jika terdapat perbedaan gait parameter pada flat foot dan cavus foot dengan melakukan exercise dan terapi yang tepat.

Melihat permasalahan yang didapat dari studi pendahuluan yang dilakukan pada anak usia sekolah dasar di Kecamatan Denpasar Barat, maka pemecahan masalah yang dapat dilakukan yaitu dengan memberikan pelayanan kesehatan fisioterapi berupa pemeriksaan tipe arkus pedis dan pemeriksaan pola berjalan pada anak usia sekolah dasar di Kecamatan Denpasar Barat, sehingga menambah wawasan dan sebagai edukasi serta masukan kepada anak-anak beserta orang tua tentang gait parameter pada anak dengan masing-masing tipe arkus pedis khususnya tipe flat foot dan cavus foot sehingga dapat memberikan informasi dini untuk modifikasi gaya hidup serta menanggulangi lebih awal jika terdapat perbedaan gait parameter pada flat foot dan cavus foot dengan melakukan exercise dan terapi yang tepat. 


\subsection{Pemeriksaan Tipe Arkus Pedis}

Tipe arkus pedis ialah tipe lengkungan arkus pada pedis yang terdiri dari tipe normal foot, flat foot, dan cavus foot. Arkus pedis kedua kaki diperiksa dengan footprint test. Pengukuran kategori normal foot, flat foot dan cavus foot menggunakan Clarke's angle. Clarke's angle diperoleh dari meghitung sudut dari garis singgung yang dibentuk oleh garis pertama yang menghubungkan tepi medial caput metatarsal pertama dan tumit serta garis kedua yang menghubungkan caput metatarsal pertama dengan puncak lengkungan arkus longitudinal medial (Pita-Fernández et al., 2015), dapat dilihat pada gambar 3.1. Pengkategorian tipe arkus berdasarkan Clarke's angle ialah sebagai berikut:
a. Normal foot memiliki rentangan $31^{\circ}-<45^{\circ}$
b. Flat foot memiliki rentangan $<31^{\circ}$
c. Cavus foot memiliki rentangan $>45^{\circ}$

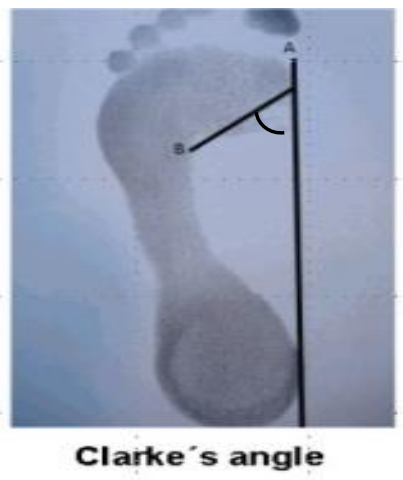

Gambar 3.1 Penilaian pedis dengan Clarke's angle (Pita-Fernández et al., 2015)

Pengukuran tipe arkus pedis dengan melakukan footprint, footprint test dengan cara kedua kaki subjek menapak matras spons yang telah berisikan tinta lalu menapakkan kedua kakinya pada kertas polos sehingga akan terlihat sidik pedis subjek. Pengukuran tipe arkus selanjutnya diperiksa dengan Clarke's angle.

\subsection{Pemeriksaan Gait Parameter}

1. Stride Length dan Step length

Stride length diukur pada jarak linear dari garis yang dibentuk oleh dua kaki sisi yang sama. Step length diukur pada jarak linear dari garis yang dibentuk oleh dua kaki sisi berbeda. Stride length dan step length dihasilkan oleh sidik pedis pada kertas polos setelah 3 langkah yang diukur dalam meter

Pengukuran parameter ini, kaki subjek diminta kembali menapak pada matras spons yang telah berisi tinta lalu berjalan di atas kertas panjang dengan tatapan menghadap ke depan serta berjalan senyaman mungkin. Sidik pedis hasil footprint test yang akan diukur ialah sidik pedis setelah 3 langkah. Kaki subjek lalu dibersihkan dari tinta foot print untuk mengukur parameter selanjutnya.

\section{Cadence}

Cadence merupakan jumlah langkah dalam waktu tertentu. Pada penelitian ini akan dihitung jumlah langkah saat subjek berjalan dalam jarak 10 meter selama satu menit yang diukur menggunakan stopwatch. Pengukuran cadence dilakukan pada permukaan yang rata.

\section{8 | BULETIN UDAYANA MENGABDI}


Peneliti lalu menghitung jumlah langkah subjek. Pengukuran untuk menilai cadence ialah subjek diminta untuk berjalan selama satu menit tanpa menggunakan alas kaki lalu akan dihitung jumlah langkah dalam satu menit. Subjek berjalan dengan tatapan menghadap ke depan serta berjalan senyaman mungkin pada permukaan yang rata.

3. Speed

Speed atau kecepatan ialah jarak yang dapat ditempuh dalam waktu tertentu. Speed atau kecepatan akan dinilai dengan hasil dari pengukuran stride length dikali dengan hasil dari pengukuran cadence pada tiap subjek. Hasil speed dalam meter perdetik $(\mathrm{m} / \mathrm{s})$. Sesuai dengan rumus:

Speed $(\mathrm{m} / \mathrm{s})=$ stride length $(\mathrm{m}) \mathrm{x}$ cadence $($ step/min $) / 120$

Pengukuran untuk menilai speed akan didapatkan setelah mendapat hasil dari parameter stride length dan parameter cadence dari subjek lalu peneliti memasukan ke dalam rumus speed.
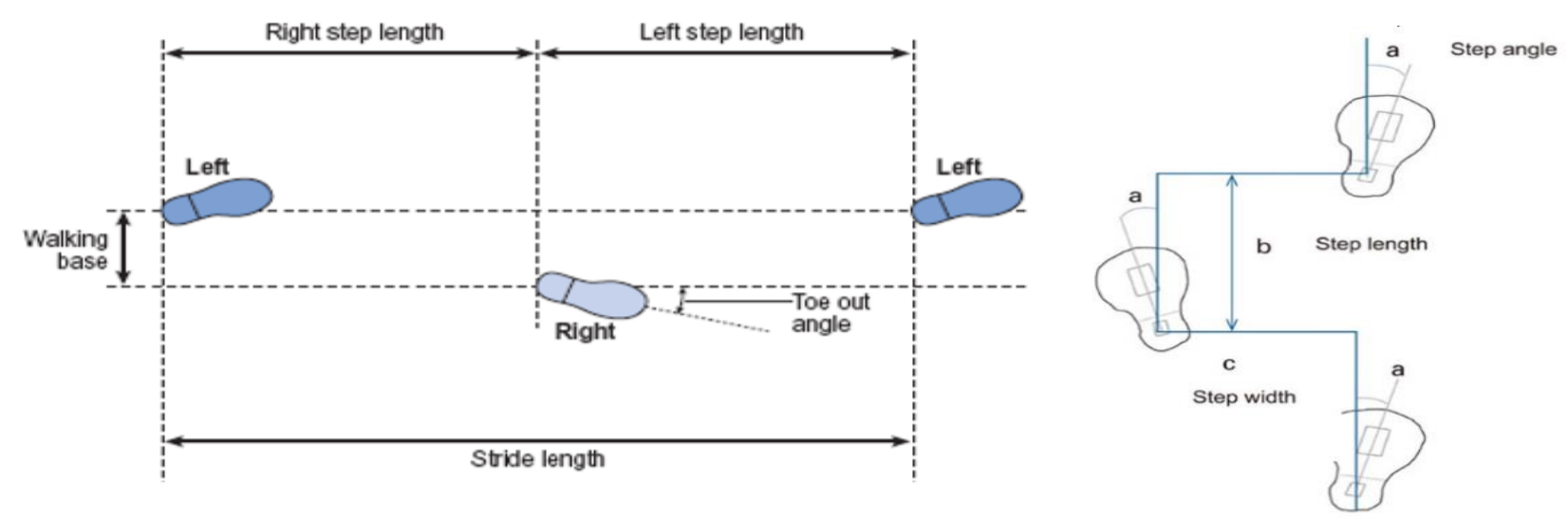

Gambar 3.2 Pemeriksaan Gait Parameter

\subsection{Hasil Pemeriksaan Arkus Pedis dan Gait Parameter}

Responden dalam pengabdian ini adalah siswa-siswi Sekolah Dasar Negeri 8 Dauh Puri. Sampel yang telah mengikuti pengabdian ini berjumlah 113 orang yang dibagi ke dalam 3 kelompok berdasarkan tipe arkus. Pengklasifikasian tipe arkus dalam penelitian ini menggunakan Clarke's Angle, sehingga didapatkan jumlah masing-masing kelompok yaitu normal foot berjumlah 40 orang, flat foot berjumlah 40 orang, dan cavus foot berjumlah 33 orang. Karakteristik yang diamati dalam pengabdian ini adalah usia, berat badan, tinggi badan, IMT/usia, panjang tungkai, jenis kelamin, cadence, stride length, step length, dan speed, pada setiap tipe arkus pedis, dapat dilihat pada Tabel 5.3.

Tabel 3.1 Karakteristik Responden

\begin{tabular}{cccc}
\hline & \multicolumn{3}{c}{ Nilai Rerata \pm Simpang Baku } \\
\cline { 2 - 4 } Karakteristik & Normal Foot & Flat Foot & Cavus Foot \\
\hline Usia (tahun) & $10,80 \pm 0,65$ & $10,95 \pm 0,68$ & $10,88 \pm 0,74$ \\
Berat Badan $(\mathrm{kg})$ & $35,53 \pm 6,53$ & $37,05 \pm 6,11$ & $36,22 \pm 6,68$ \\
Tinggi Badan $(\mathrm{m})$ & $1,43 \pm 0,09$ & $1,43 \pm 0,07$ & $1,45 \pm 0,12$ \\
IMT/usia & $17,31 \pm 1,79$ & $17,96 \pm 1,79$ & $17,43 \pm 1,99$ \\
Panjang Tungkai (cm) & $74,86 \pm 4,58$ & $75,67 \pm 3,87$ & $76,00 \pm 4,26$
\end{tabular}




\begin{tabular}{cccc} 
Laki-laki & $24(60 \%)$ & $16(40 \%)$ & $18(55,5 \%)$ \\
Perempuan & $16(40 \%)$ & $24(60 \%)$ & $15(45,5 \%)$ \\
\hline
\end{tabular}

Tabel 3.1 menunjukan bahwa responden pada kelompok normal foot memiliki nilai rerata usia dan simpang baku $(10,80 \pm 0,65)$, kelompok flat foot $(10,95 \pm 0,68)$, dan kelompok cavus foot $(10,88 \pm 0,74)$. Pada kelompok normal foot responden memiliki nilai rerata berat badan dan simpang baku $(35,53 \pm 6,53)$, kelompok flat foot $(37,05 \pm 6,11)$, dan kelompok cavus foot $(36,22 \pm 6,68)$. Pada kelompok flat foot, responden memiliki rata-rata berat badan yang paling besar dibandingkan kelompok cavus foot dan kelompok normal foot. Berdasarkan tinggi badan didapatkan rerata dan simpang baku pada kelompok normal foot $(1,43 \pm 0,09)$, kelompok flat foot $(1,43 \pm 0,07)$, kelompok cavus foot $(1,45 \pm 0,12)$. Rata-rata tinggi badan tertinggi dimiliki oleh kelompok cavus foot dan kelompok normal foot dan flat foot memiliki nilai yang sama. Rerata dan simpang baku IMT/usia pada kelompok normal foot $(17,31 \pm 1,79)$, kelompok flat foot $(17,96 \pm 1,79)$, dan kelompok cavus foot $(17,43 \pm 1,99)$. Rata-rata IMT tertinggi dimiliki oleh kelompok flat foot dan terendah dimiliki oleh kelompok normal foot. Panjang tungkai pada kelompok normal foot memiliki nilai rerata dan simpang baku $(74,86 \pm 4,58)$, kelompok flat foot $(75,67 \pm 3,87)$, dan kelompok cavus foot $(76,00 \pm 4,26)$.

Jumlah dan persentase jenis kelamin pada kelompok normal foot ialah laki-laki sebanyak 24 orang $(60 \%)$ dan perempuan 16 orang $(40 \%)$, pada kelompok flat foot dengan laki-laki sebanyak 16 orang $(40 \%)$ dan perempuan 24 orang $(60 \%)$, sedangkan kelompok cavus foot jumlah laki-laki 18 orang $(55,5 \%)$ dan perempuan 15 orang $(44,5 \%)$.

Tabel 3.2 Hasil Rerata dan Simpang Baku Gait Parameter

\begin{tabular}{cccc}
\hline & \multicolumn{3}{c}{ Nilai Rerata \pm Simpang Baku } \\
Karakteristik & Normal Foot & Flat Foot & Cavus Foot \\
\hline Cadence & $104,05 \pm 8,69$ & $96,82 \pm 5,67$ & $95,21 \pm 7,24$ \\
Stride Length & $0,97 \pm 0,18$ & $0,85 \pm 0,13$ & $0,84 \pm 0,12$ \\
Step Length & $0,48 \pm 0,08$ & $0,42 \pm 0,07$ & $0,42 \pm 0,06$ \\
Speed & $0,84 \pm 0,18$ & $0,69 \pm 0,12$ & $0,66 \pm 0,11$ \\
\hline
\end{tabular}

Berdasarkan Tabel 3.2 dapat dilihat gambaran nilai rerata dan simpang baku gait parameter yang terdiri dari cadence, stride length, step length dan speed. Nilai rerata cadence dan simpang baku pada kelompok normal foot $(104,5 \pm 8,69)$, kelompok flat foot $(96,82 \pm 5,66)$, dan kelompok cavus foot $(95,21 \pm 7,24)$. Nilai rerata dan simpang baku stride length pada kelompok normal foot $(0,97 \pm 0,18)$, kelompok flat foot $(0,85 \pm 0,13)$, dan kelompok cavus foot $(0,84 \pm 0,12)$. Pada variabel step length, kelompok normal foot memiliki rerata $(0,48 \pm 0,08)$, kelompok flat foot $(0,42 \pm 0,07)$, dan kelompok cavus foot $(0,42 \pm 0,64)$. Variabel gait parameter yang terakhir ialah speed. Speed pada diketiga kelompok memiliki nilai rerata dan simpang baku seperti berikut normal foot $(0,84 \pm 0,11)$, kelompok flat foot $(0,68 \pm 0,12)$, dan kelompok cavus foot $(0,66 \pm 0,11)$.

Berikut beberapa dokumentasi terkait pengabdian masyarakat yang telah dilakukan. 


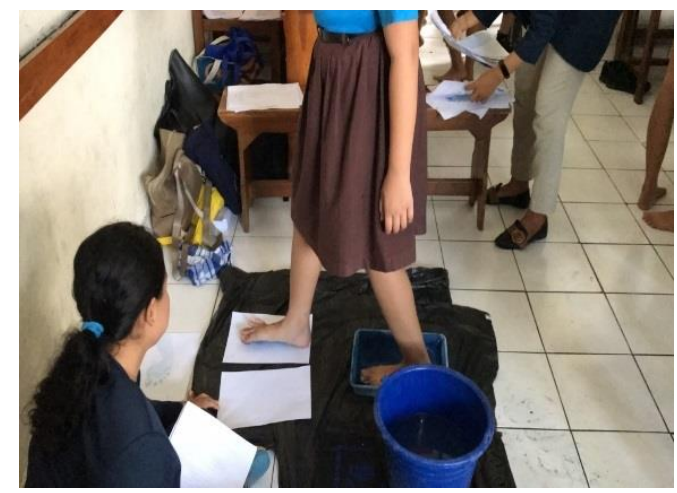

Gambar 3.3 Pemeriksaan tipe arkus pedis di SDN 8 Dauh Puri

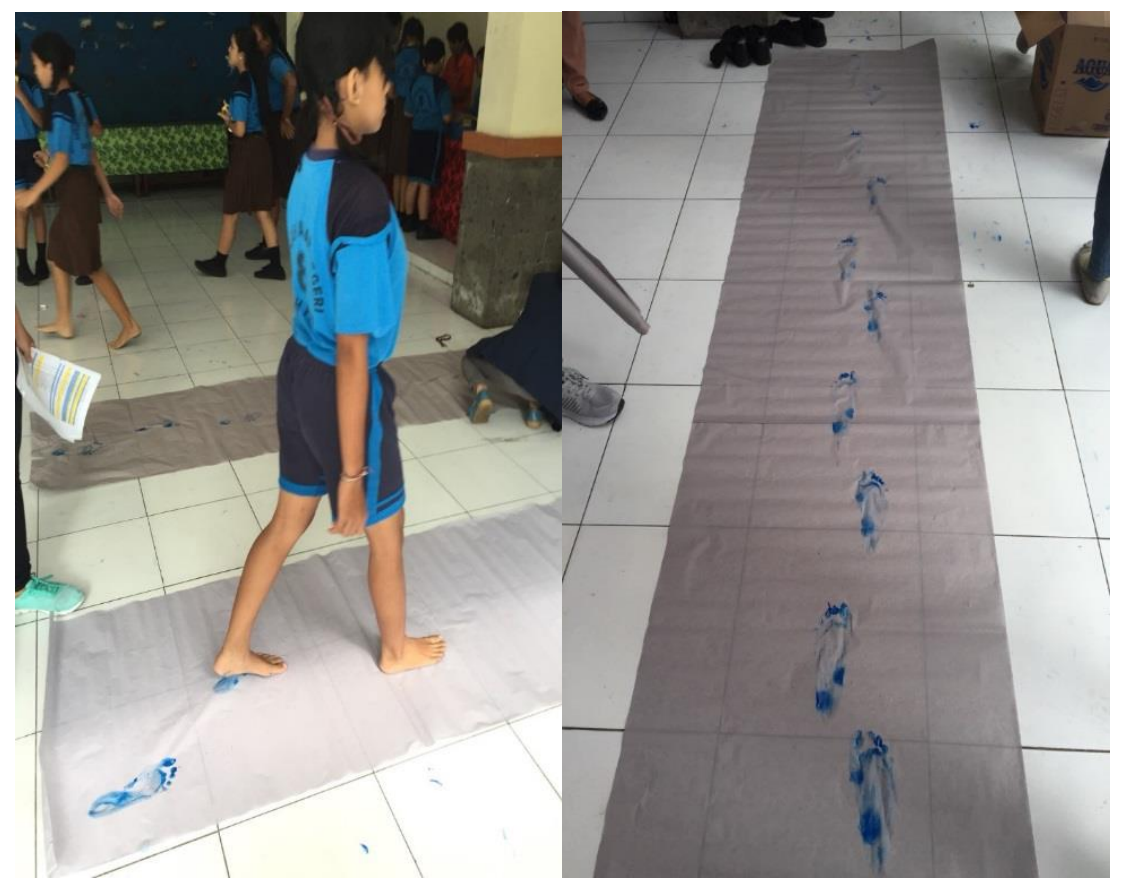

Gambar 3.4 Pemeriksaan gait parameter di SDN 8 Dauh Puri

\section{KESIMPULAN DAN SARAN}

Berdasarkan hasil dan pembahasan di atas, maka dapat disimpulkan bahwa:

1) Sampel mengikuti pengabdian ini berjumlah 113 orang yang terdiri atas: normal foot berjumlah 40 orang, flat foot berjumlah 40 orang, dan cavus foot berjumlah 33 orang.

2) Tipe normal foot memiliki nilai cadence (jumlah langkah), stride length, step length, dan speed yang lebih besar dari pada flat foot dan cavus foot.

\section{UCAPAN TERIMA KASIH}

Terima kasih penulis ucapkan kepada Unit Penelitian dan Pengabdian pada Masyarakat (UPPM) Fakultas Kedokteran Universitas Udayana atas hilirisasi hasil penelitian untuk meningkatkan pengetahuan kesehatan. 


\section{DAFTAR PUSTAKA}

Kharb, A., Saini, V., Jain, Y., \& Dhiman, S. (2011). A Review Of Gait Cycle And Its Parameters. Ijcem Int J Comput Eng Manag, 13(July), 78-83. Https://Doi.Org/10.1007/3-540-49384-0_1

Neumann, D. A. (2010). Kinesiology Of The Musculoskeletal System (2 Ed.).

Nishimura, H., Endo, K., Suzuki, H., Tanaka, H., Shishido, T., \& Yamamoto, K. (2015). Gait Analysis In Cervical Spondylotic Myelopathy. Asian Spine Journal, 9(3), 321-326. Https://Doi.Org/10.4184/Asj.2015.9.3.321

Nugroho, D. A. (2012). Upaya Meningkatkan Kemampuan Gerak Dasar Lokomotor Melalui Aplikasi Permainan Beregu Pada Siswa Kelas Iii Sd Negeri 1 Gancang Kecamatan Gumelar Kabupaten Banyumas Tahun Pelajaran 2011/2012. Diambil Dari Https://Media.Neliti.Com/Media/Publications/13899-Id-Upaya Meningkatkan-KemampuanGerak-Dasar-Lokomotor-Melalui-Aplikasi-Permainan-Be.Pdf

Nurohman, M. A., Moerjono, S., \& Basuki, R. (2017). Hubungan Tinggi Lompatan Dan Bentuk Arcus Pedis Dengan Kejadian Sprain Pergelangan Kaki Pada Atlet Bulutangkis Yang Melakukan Jumping Smash. Diambil Dari Http://Repository.Unimus.Ac.Id

Permatasari, G. A., \& Winarni, T. I. (2017). Perbedaan Pengaruh Sepatu Berhak Wedge Dan NonWedge Terhadap Gait Dan Keseimbangan. Jurnal Kedokteran Diponegoro, 6(2), 576-582.

Pita-Fernández, S. González-Martín, C. Seoane-Pillado, T. López-Calviño, B. Pértega-Díaz, S. dan Gil-Guillén, V. (2015). Validity of Footprint Analysis to Determine Flatfoot Using Clinical Diagnosis as the Gold Standard in a Random Sample Aged 40 Years and Older. J Epidemiol 2015;25(2):148-154

Suhartini, B. (2005). Deteksi Dini Keterlambatan Perkembangan Motorik Kasar Pada Anak. Medikora, 1(2), 177-185. Diambil Dari Https://Journal.Uny.Ac.Id/Index.Php/Medikora/Article/Viewfile/4770/4128

Zulham, M. (2016). Hubungan Struktur Pedis Dengan Kecepatan Lari 60 Meter Pada Siswa SMA Negeri 3 Semarang Karya Tulis Ilmiah. Universitas Diponegoro.

\section{2 | BULETIN UDAYANA MENGABDI}

